through the peritoneum and placed equidistantly round the opening, pressure forceps being applied to each. This prevents the peritoneum sinking down when the stomach is withdrawn. Three inches of stomach, as near the cardiac end as possible, are drawn out ; the peritoneum and aponeurosis are carefully stitched to the stomach, using a Reverdin's curved needle; the stomach is then opened and a No. 12 soft catheter is introduced and fixed in position by a fine suture which passes through the whole thickness of the stomach wall and is tied tightly round the catheter. The stomach is now invaginated by pressing upon the firmly secured tube and a purse-string suture is introduced a quarter of an inch below the opening into the stomach. This is drawn up and tightened round the tube; a second purse-string suture is introduced half an inch below the first, the stomach being further invaginated and the stitches tightened around the tube; a third purse-string is introduced half an inch below the second if necessary and tied round the tube. In this way a valve is formed inside the stomach so that the tube can be easily passed in, and when removed the valve comes together and completely closes the opening. The skin incision is united with silkworm gut. After the wound is healed the patient soon learns to feed himself. Having first chewed the food he passes it into the tube which is inserted into the stomach. Those interested in this subject will see two good plates illustrating the operation in Kocher's recent work on Operative Surgery translated by Stiles.

Glasgow.

\section{A CASE OF INJURY TO THE BACK FOLLOWED BY ALL THE APPEARANCES OF SYRINGOMYELIA.}

By Charles Mackie Bege, M.B., L.R.C.P. Edin,, HOUSE SURGEON, BOROUGH HOSPITAL, BIRKENHEAD.

A MAN, aged 37 years, was struck on the back by a sack of corn which fell from a height of over 30 feet. He was admitted to the Birkenhead Borough Hospital on June 6th, the day of the accident. There was severe bruising over the back of the neck and chest. No irregularity of the vertebral column could be discovered and there were no symptoms pointing to any injury of the spinal cord. The patient was a very powerfully built man and stated that he had previously enjoyed perfect health.

Recovery went on apparently uninterruptedly till June 12th when he complained of some weakness in the arms and legs. On examination the knee-jerks were found to be brisk. On the 20th there was marked wasting of the muscles of the thenar and hypothenar eminences of both hands and the grasp was distinctly weak. The legs were becoming spastic and there was some diminution of the heat and cold and pain senses on both sides. His condition became worse, the spasticity of his legs increased, and the wasting of the muscles of the forearms and hands became very marked. On the 30th his condition was as follows. In the upper extremities there was marked wasting of the small muscles of both hands and of the flexors and to a lesser degree the extensors of the forearms. The pronators and supinators were very slightly, if at all. affected. The biceps, triceps, and deltoid were slightly wasted but not nearly to the same extent as the muscles of the forearm. The affected muscles reacted sluggishly to electricity. Both biceps. and triceps-jerks could be elicited. There was no impairment of any of the senses in the arms. In the lower extremities the muscles were spastic, both knee-jerks were much increased, the ankle and patellar clonus was marked, and Babinski's plantar reflex was present in both feet. With great difficulty the patient could raise his legs about three inches from the bed. There was slight delay in the conduction of tactile sensations. The muscular sense was unimpaired. Sensation to pain was diminished in both legs and the difference between heat and cold was not appreciated. There was some weakness of the abdominal muscles, the patient being quite unable to sit up in bed. The bladder and rectum were unaffected.

The further progress of the case was as follows. On July 8th the patient could sit up in bed without assistance and his grasp was slightly stronger. There was some fibrillary twitching of the tongue and his speech was not so distinct as before. There was no improvement in the wasted muscles of the hand.
The case presents most of the symptoms and signs of syringomyelia. The unusual features are the rapidity of the onset and the severity of the affection of the legs. The lesion was evidently in the seventh and eighth cervical and first dorsal segments of the cord. Is it possible that the cause might be a small hæmorrhage in the grey matter, producing destruction of the trophic centres for the muscles of the arms and by its pressure causing degeneration of the crossed pyramidal tracts? If so, the hæmorrhage or the resulting myelitis must have cut off the conducting tracts of the heat and cold and pain senses from the lower limbs. It is possible that the patient may have had a dilatation of the central canal previously. This may have caused no symptoms till the blow on the back produced effusion or slight hæmorrhage into the cavity.

I am indebted to Dr. W. R. Floyd, under whose care the patient was, for permission to use these notes.

Birkenhead.

\section{A 3 thitror}

$\mathrm{OF}$

\section{HOSPITAL PRACTICE, BRITISH AND FOREIGN.}

Nulla autem est alia pro certo noscendi via, nisi quamplurimas et morborum et dissectionum historias, tum aliorum tum proprias collectas habere, et inter se comparare.-MoRgaGNI De Sed. et Caus. Mrorb., lib. iv., Procmium.

\section{ST. GEORGE'S HOSPITAL.}

NINE CONSECUTIVE CASES OF PERFORATED GASTRIC ULCER TREATED BY SUTURE, IRRIGATION, AND DRAINAGE,

(Seven under the care of Mr. G. R. TuRnER and two under the care of Mr. T. CRIsP ENGLISH; eight recoveries.)

For the notes of the cases we are indebted to Mr. Crisp English.

CAsE 1.-The patient, a woman, aged 24 years, was admitted to hospital under the care of Mr. Turner on Nov. 28th, 1900, with the following history. At 9 P.M. on the previous evening she was frightened by a mouse and immediately after was seized with acute epigastric pain followed by vomiting. On admission she looked extremely ill and was in great pain. The temperature was $99 \cdot 5^{\circ} \mathrm{F}$. and the pulse was 120 . The abdomen was rigid, distended, and tympanitic. Acute tenderness was present in the epigastrium. Liver dulness was absent.

Operation.--Median laparotomy was performed above the umbilicus. Gastric perforation was found on the anterior surface of the greater curvature near the cesophageal end. There were much foul fluid and lymph in the peritoneal cavity. The perforation was closed and a counter opening was made below the umbilicus. Three drainage-tubes were inserted. On the fourteenth day after operation thrombosis occurred in the left calf; convalescence was otherwise uneventful and the patient went to the Wimbledon Convalescent Home on Jan. 9th.

CASE 2.-The patient was admitted to hospital under the care of Mr. Turner on March 5th, 1901, with a history of acute abdominal pain for two days. The pain had been sudden in onset and was situated in the epigastrium; the abdomen had become distended and vomiting had occurred twice. On admission the patient, who was sent by rail about 100 miles to hospital, looked very ill, complaining of great pain and thirst; the marked abdominal face was present; the temperature was $97^{\circ} \mathrm{F}$. and the pulse was 130 . The abdomen was greatly distended, chiefly in the lower part; it was immobile, rery tender, and rigid. Liver dulness was diminished. There was moveable dulness in the flanks.

Operation.-A median incision was made. Intense general peritonitis was found. Escape of large quantities of fluid and free gas led the way to a large perforation on the anterior surface of the stomach close to the cesophageal end. As the patient's condition was very bad a gauze plug was passed to the perforation and the peritoneal cavity was flushed out with hot saline solution; drainage-tubes were inserted and the wound was sutured. Death occurred a few hours later. 
CasE 3.-The patient, a girl, aged 17 years, was admitted to hospital under the care of Mr. Turner on Feb. 17th, 1902. The following history was given. She had had pain and vomiting after food for four months. On Feb. 15th after a small meal she was suddenly seized with acute pain in the epigastrium and vomited several times. The pain continued until the time of admission but no further vomiting occurred. On admission she was found to be a very anæmic girl. The temperature was $103^{\circ} \mathrm{F}$. and the pulse was 140. The abdomen was very tender all over, especially in the left hypochondrium. It was slightly rigid but not much distended ; there was fair movement on respiration splashing sounds were heard. Tubular breathing and dulness were present over the lower part of the left lung.

Operation.-A median epigastric incision was made. There were much straw-coloured fluid and free gas in the peritoneal cavity. A small perforation was found near the œsophageal end of the stomach on the posterior surface close to the aorta; there were many adhesions around. Gauze packing was passed to the perforation. A second opening was made in the hypogastrium; much foul fluid was sponged out, with general irrigation with weak boric lotion. Drainage-tubes were passed into the pelvis and into each flank. There was much bronchitis during the week after operation; thrombosis occurred in the left calf during the third week. The patient was discharged from hospital on the thirty-second day.

At the present time she is in excellent health and has had no return of gastric symptoms. In September last she was seen for superficial varicose veins of the leg (following the thrombosis) and was ordered an elastic stocking.

CASE 4.-The patient, a female, aged 25 years, was admitted to hospital under the care of Mr. Turner, on Nov. 12th, 1902. She had had pain after meals and vomiting for three weeks and had been treated as a medical out-patient on this day. Whilst waiting at the dispensary for her medicine she was suddenly seized with violent pain and became collapsed; vomiting occurred. She gave a history of some indigestion for years but had never had hæmatemesis. On arlmission she was pale, collapsed, and sweating; the abdomen was boardlike and immobile; there was exquisite tenderness and the liver dulness was absent.

Operation.-This was performed about four hours after perforation. A median epigastric incision was made. A chronic ulcer was found on the anterior wall near the cardiac end; it was a small ragged perforation. Gastric contents were present in the peritoneal cavity and especially in Douglas's pouch. Closure was effected with a double row of sutures. Two drainage-tubes were inserted. A suprapubic incision was made and general irrigation was carried out by means of a large tube placed in Douglas's pouch. Recovery was uneventful.

CASE 5.--The patient, a married woman, aged 23 years, was admitted to hospital under the care of Mr. Turner on Jan. 5th, 1903, with the following history. On Jan. 4th there was slight pain and she romited. At midnight there was sudden violent pain in the epigastrium with collapse. At 5 A.M. she vomited once; the pain continued. She had been constipated since the 3rd. She had had indigestion for 18 months; she had also had hæmatemesis on three occasions, the last time being four weeks before. On admission she was anæmic and looked very ill. The temperature was $102^{\circ} \mathrm{F}$. and the pulse was 120 . The abdomen was distended below the umbilicus. There was slight epigastric movement only. There were general tenderness and rigidity. The liver dulness was normal.

Operation.--This was performed 17 hours after perforation. A median incision was made above the umbilicus; extensive peritonitis was found. There was a perforation on the anterior surface one and a half inches below the centre of the lesser curvature. The perforation was closed with Lembert sutures. A counter opening was made in the lower abdomen. The pelvis contained much turbid fluid. General irrigation was carried out; tubes were inserted into each flank and into the pelvis; gauze was passed down to the site of the perforation. Convalescence was uneventful. The patient was seen two months later. She had had no return of the gastric symptoms. She was fatter and healthier. The scars were sound.

CASE 6.-The patient, a vanman, aged 23 vears, was admitted to hospital under the care of Mr. "Turner on April 25th, 1904, with the following history. He had had pain in the right side for one week. At $10.30^{\circ}$. I. on the day of admission there was sudden acute pain as if he had been stabbed with a knife; this occurred whilst he was getting into a van; there was no vomiting. He took some brandy and a druggist gave him some medicine for the pain (? morphine). There was no history of dyspepsia or hæmatemesis. On admission the patient walked into the surgery looking very ill. There were tenderness and rigidity over the right side of the abdomen, especially over the right iliac fossa and also on a level with the umbilicus. Pain was referred to a point one inch above McBurney's point. Respiratory movements were catchy; liver dulness was normal. There was much bronchitis. In the evening the temperature rose to $103^{\circ} \mathrm{F}$. The pain was still severe; there was no vomiting

Operation.-This was performed at 8.30 P.M. (ten hours after perforation). Owing to the obscurity of the symptoms and signs Mr. Turner decided first to examine the appendix. Incision was made through the right semilunar line. A quantity of free fluid was found; there was no free gas. The omentum was inflamed. The appendix, which was very long, was lying in a little pool of purulent fluid; it contained fæcal material and was removed. Further search showed lymph and matted omentum in the upper part of the abdomen. A median epigastric incision was made. A round clean-cut perforation, one-third of an inch in diameter, was found near the pylorus close to the great curvature. Closure was very difficult owing to the friability of the gastric wall; about eight Lembert sutures were used. A second incision was made in the mid-line above the pubes. The pelvis was found to be full of gastric fluid. Drainagetubes were inserted and general irrigation was performed. A gauze plug was passed to the site of the perforation. Severe bronchitis followed. On the 28th some gauze was removed. On the 29th albumin, water, and beef-tea were given by the mouth. On the 30th smaller tubes were inserted. On May 4th all tubes were removed. The patient was discharged on May 23rd.

CASE 7.-The patient, a female, aged 22 years, was admitted to hospital on May 29th, 1899, under the care of Dr. Rolleston. The following history was given. Whilst walking in the street she was suddenly seized with violent pain in the left hypochondrium; she was at once carried into hospital and shortly after admission vomited twice. She had suffered from dyspepsia for about three years and had had two attacks of pleurisy. On admission she had the facies abdominalis. There was severe pain in the epigastrium and left shoulder. The temperature was $99 \cdot 2^{\circ} \mathrm{F}$. and the pulse was 128. The abdomen was slightly distended and moved but little on respiration; it was tender and rigid all over, especially in the epigastrium. Liver dulness was diminished. Expectant treatment was adopted. The abdomen became more distended, the pulse rose to 160 , and the pain remained severe. The patient was very restless and vomited twice. Mr. Turner operated on the following morning.

Operation.--The abdomen was opened in the left hypochondrium. Purulent fluid and stomach contents were found to be escaping from the posterior wall of the stomach. The actual perforation was not seen. Gauze packing was inserted. A counter opening was made in the loin and two drainage-tubes were put in. Pleurisy occurred on the left side on June 8th ; convalescence was otherwise uneventful. 'The patient was discharged on July 26th.

CAsE 8.-The patient, a woman, aged 32 years, was admitted to hospital under the care of Mr. Crisp English on the evening of Jan. 25th, 1904. She had had dyspepsia for 18 months. Hæmatemesis had never been present. The pain had been worse for three weeks but there had been no vomiting. At $9 \mathrm{~A} . \mathrm{M}$. on the 25th, one hour after breakfast, the patient had sudden violent pain in the epigastrium with the sense of something giving way. There was much nausea but no vomiting. The pain had become diffused. On admission the patient was thin, looking ill and flushed; her eyes were sunken. The temperature was $101.6^{\circ} \mathrm{F}$. and the pulse was 88 . The abdomen was retracted; general rigidity and tenderness were present. The pain was acute and referred to the left side of the epigastrium. Liver dulness was normal.

operation.-This was performed 12 hours after perforation. An epigastric incision was made through the left rectus. There was no escape of free gas. Much gastric fluid was seen with gas bubbles. The perforation was found two inches from the osophageal end of the stomach on the anterior surface and just below the lesser curvature. There was much friable tissue around. The perforation was closed with a double row of sutures and a piece of 
omentum was sewn over. A second incision was made above the pubes. Large quantities of turbid fluid were found in the pelvis. General irrigation was carried out with drainagetubes. Recovery was uneventful. The patient was sent to the convalescent home on the thirtieth day.

CASE 9.-A woman, aged 27 years, was admitted to hospital under the care of Mr. Crisp English during the night of March 25th, 1904. As history, it was stated that at $12.30 \mathrm{~A}$.M. she woke up feeling very faint, having severe pain in the right hypochondrium and hypogastrium. There was no vomiting. She was seen by Dr. H. R. Fuller shortly afterwards and sent at once to hospital. She had suffered from dyspepsia for three months, this being especially bad for the three days before admission. On admission she was anæmic and looked extremely ill. The extremities were cold. The temperature was $96^{\circ} 4^{\circ} \mathrm{F}$. and the pulse was 78 . Pain was present in the epigastrium and right shoulder. There were general tenderness and rigility of the abdomen, mostly in the lower part. Some distension was present below the umbilicus. Liver dulness was absent.

Operation.-This was performed five and a half hours after the perforation occurred. An incision was made through the upper part of the left rectus. Free gas and gastric fluid immediately escaped. The perforation was readily found on the anterior surface one inch from the pylorus; it was clean cut and of the size of a threepenny piece. This was sutured and a fringe of omentum was sewn over it. A second incision was made in the hypogastrium. Much gastric fluid was found in Douglas's pouch. General irrigation was carried out with drainage-tubes. Recovery was uneventful. The patient was sent to the convalescent home on the twentysixth day.

Remarks by Mr. 'TuREER.--All the cases with the exception of the leaking subphrenic abscess (Case 7) were treated in the same way. The ulcers when found were first of all sutured as rapidly as possible without paying undue attention to the non-inclusion of the mucous membrane or carrying the suture for any distance beyond the limits of the perforation. In nearly all the suture was subsequently strengthened by a few Lembert stitches. Each case, except the one referred to above, was treated by free irrigation, warm sterilised water or weak boric lotion being used, after provision had been made for drainage, not only at the seat of the wound but in the suprapubic region and the flanks, and this irrigation was continued until the outflowing fluid was absolutely clear. The peritoneal cavity has been irrigated in this way by as much as 14 or 16 pints. Irrigation was designedly omitted in Case 7 (leaking subphrenic abscess); the contaminated parts, however, were cleaned by simple sponging. Irrigation, where there is any localised collection of foul septic pus, on account of the danger of dissemination is not to be recommended.

Drainage-tubes as large as the middle finger (usually three in number) were inserted: (1) above the pubes, (2) down to the seat of the ulcer, and (3) in one or both kidney pouches. In the case where the appendix was the seat of a fæcal concretion and was removed a clrainage-tube was passed through the right linea semilunaris. ${ }^{1}$ In nearly all the cases the suprapubic drainage disclosed a pelvic collection of peritoneal fluid and stomach contents.

Only one of the perforations was not sutured; that one was on the posterior surface of the stomach close to the csophageal end, in the immediate neighbourhood of the aorta ; the anatomy of the surrounding parts was much obscured by adhesions and inflammatory changes, and it was deemed safer to treat the case by gauze packing.

It is not claimed that the subsequent drainage had much to do with the success of these cases but the incisions made for this purpose most undonbtedly allow at the time of the operation a complete and thorough searching out of any little peritoneal pouch or pocket that might otherwise escape irrigation and has largely contributed to the eventual recovery of the patients. The one patient who died had come a long way from the country and was practically moribund at the time of the operation. All the eight cases in which there was any chance of recovery have recovered.

Mr. English's cases ( 8 and 9 ) were treated in the same way with the trifling exception that an omental graft was used to help to close the perforation.

I Since writing the above I have had a successful case of perficated duodenal ulcer, in which there was a'so appendicitis, treated in the same way and which has recoverel.

\section{BRISTOL GENERAL HOSPITAL.}

\section{A CASE OF TUBERCULOUS ULCERATION OF THE INTESTINES} CAUSING MULTIPLE STRICTURE, ATTENDED BY MELANCHOLIA ; PERFORATION ; PERITONITIS ; DEATH.

(Under the care of Dr. J. Michelt ClaRke.)

For the notes of the case we are indebted to Dr. A. Rendle Short, house physician.

The patient, a man, aged 29 years, was admitted into the Bristol General Hospital on Jan. 7th, 1904, complaining of pain in the stomach, sickness, and constipation of three years' duration. He stated that previously to this he never had any illness and had not had any cough. His parents and brothers and sisters were all living and well, and there was no disease in the family. He was married but had no children. Three years previously he began to have attacks of sharp pain in the abdomen when he was overtired, so severe as "to double him up." The pain was situated just below the umbilicus. This had continued ever since and was at the time of admission worse than before. He had had more or less pain every day. During the last 12 months it had been worse after food, especially solids; it was not markedly relieved by vomiting and was worse when the bowels were confined. $\mathrm{He}$ had also been suffering from attacks of vomiting for the same length of time, chiefly after solid food; usually about half an hour after a meal but sometimes immediately. The bowels had been costive and for one month had only been opened by enema; previously to this they were opened every other day. He had also suffered from flatulence. 'The motions contained no mucus; they had contained blood but he had piles. 'They had been black but never tarry (he had been taking medicines, probably bismuth). He had never had any hæmatemesis. There was no jaundice or hæmaturia. Three years ago he weighed 9 stones, now he weighed 7 stones 10 pounds. He had been very depressed of late.

On admission the patient was pale and ill-nourished, with a very melancholy expression. His appetite was poor and he slept badly. The tongue was clean and moist. There was no fever. The heart and lungs were normal except that the apex beat and first heart sound were feeble; the pulse was soft. The abdomen was moderately distended, especially in the epigastrium. No masses or tumours were felt. The liver and spleen were normal. There was no ascites. Peristaltic movements were visible in the intestines. There was some gurgling all over the abdomen. Nothing abnormal was felt per rectum; there was no ballooning of the rectum. The motions were hard, scybalous, pale, and contained no mucus or blood. The urine contained no albumin or sugar. The patient was kept in bed on a light diet and given saline aperients, belladonna, and salol. Hypnotics were necessary to procure sleep.

The further progress of the case was as follows. On Jan. 18th the patient complained of but little pain but chiefly of having lost his memory and of inability to concentrate his attention or to read; when questioned he almost gave way to tears. The bowels were opened only by enema; there was no change in the character of the motions. The temperature was rather irregular, occasionally rising to $99.5^{\circ} \mathrm{F}$. or even $100^{\circ}$ at night. No more peristaltic movements in the abdomen were seen. The patient had only vomited once or twice. On the 25 th it was noted that he was very miserable; he said that he could not remember anything and entreated that his pulse should be felt because it was so weak. He prepared the following note for the visiting physician: "Doctor,-My mind and memory are quite gone. I cannot read; directly I read a sentence I forget it. ..... I cannot think of a single thing to say and if anyone says anything to me I don't understand. Although there are so many around me I am quite alone. I can hear talking going on, but don't understand what it is about. ...... I am losing every sense I possess-sight, hearing, memory, taste, feeling. ..... Pains and sickness returning. As soon as I see anything to eat I feel sick. I can't sleep. ..... Bowels very, very loose; the last time I had a motion with a lot of blood. ...... It is awful. Have pity on me, doctor. and send me away to die among my own. ...... It has taken me two and a half hours to write this." The motions had been loose and one was streaked with blood, probably from the piles, but there was no bloor present in the others. On 